\title{
A decade of experience with injuries to the gallbladder
}

\author{
Chad G Ball*1, Elijah Dixon'1, Andrew W Kirkpatrick' , Francis R Sutherland1', Kevin B Laupland² and David V Feliciano³
}

\begin{abstract}
Background: Considering that injuries to the gallbladder are rare, the purpose of this study was to evaluate injury patterns, operative procedures and outcomes in patients with trauma to the gallbladder. A retrospective review of traumatic injuries to the gallbladder at an urban level 1 trauma center from 1996 to 2008 was performed. Injuries were identified via imaging or during operative exploration.
\end{abstract}

Results: Injuries to the gallbladder occurred in 45 patients, 40 (89\%) of whom suffered penetrating trauma. Associated injuries were present in 44 (98\%) patients, including 10 (22\%) pancreatic injuries requiring repair and/or drainage. Patients were severely injured (49\% hemodynamically unstable at presentation; mean Injury Severity Score = 20; mean length of stay $=22$ days; mortality rate $=24 \%$ ). Cholecystectomy was performed in 42 patients (93\%), while the remaining 3 had drainage only as part of a "damage control" operation related to their critical physiologic status. Injuries to the extrahepatic biliary ducts occurred in 3 patients (7\%) as well. Although all patients developed trauma related complications, none were a direct result of their biliary tract injuries.

Conclusion: Injuries to the gallbladder are rare even in the busiest urban trauma centers. Almost all patients have associated intra-abdominal injuries, and nearly $50 \%$ of patients are hemodynamically unstable on admission. Rapid cholecystectomy is the treatment of choice for all mechanisms of injury, except when the first operative procedure is of the damage control type.

\section{Introduction}

Trauma to the gallbladder is rare even in the busiest centers. This likely relates to its inherent surrounding protection afforded by the liver, intestines, omentum and thoracic cage. As a result, injuries tend to be a result of direct blows, acceleration/deceleration shearing, or more commonly penetrating mechanisms [1,2]. Gallbladder trauma also tends to occur in association with multiple concurrent intra-abdominal injuries $[1,2]$.

Although the gallbladder plays a central role in the storage, concentration and regulation of bile, it is also an organ that can be removed [3]. Furthermore, because concurrent gallbladder diseases such as cholecystitis or choleduodenal fistulas are extremely rare in the injured patient, cholecystectomies can be completed rapidly. This procedure is extremely safe, with an associated bile duct injury rate of less than 1\% [2] and the occurrence of

\footnotetext{
* Correspondence: ball.chad@gmail.com

1 Department of Surgery, University of Calgary, Calgary, Alberta, Canada Full list of author information is available at the end of the article
}

associated chronic post-cholecystectomy diarrhea in 5\% to $18 \%$ of patients $[4,5]$.

The primary goal of this study was to evaluate injury patterns, operative procedures and outcomes in patients with trauma to the gallbladder.

\section{Methods}

The study population consisted of all patients (blunt and penetrating) treated at level 1 urban trauma center (Grady Memorial Hospital), between January 1, 1996 and December 31, 2008, with injuries to their gallbladder. Patient demographics, injury characteristics and outcomes were each obtained via the trauma registry and patient charts. Exclusion criteria included any patient without a gallbladder injury, as well as those who arrived without signs of life. This retrospective analysis was intended to be primarily descriptive. It was also approved by our institutional ethics review board.

Analysis was performed using Stata version 8.0 (Stata Corp, College Station, TX.). Normally or near-normally distributed variables were reported as means and non- 
normally distributed variables as medians. Means were compared using the student's $t$ test and medians using the Mann-Whitney U test. Differences in proportions among categorical data were assessed using Fischer's exact test. A p value less than 0.05 was considered to represent statistical significance for all comparisons.

\section{Results}

Records for 45 patients with gallbladder injuries were available for the 13-year study period (Table 1). Penetrating mechanisms were responsible for $89 \%$ of cases $(24$ gunshot wounds, 16 stab wounds). The remaining 5 patients were struck by vehicles (3) or involved in motor

\section{Table 1: Patient demographics and injury characteristics}

\begin{tabular}{|c|c|}
\hline Total patients & 45 \\
\hline Mean Age & 27 years (SD: 8.69) \\
\hline Male & $87 \%$ \\
\hline Median Injury Severity Score & 20 (range: 9-41) \\
\hline Hemodynamic Instability & $49 \%$ \\
\hline $\begin{array}{l}\text { Median Length of Stay } \\
\text { (hospital) }\end{array}$ & 22 days (range: $0-108$ ) \\
\hline Median Length of Stay (ICU) & 12 days (range: $1-107$ ) \\
\hline Mortality & $24 \%$ \\
\hline $\begin{array}{l}\text { Penetrating Mechanism of } \\
\text { Injury }\end{array}$ & $89 \%$ \\
\hline Gunshot Wounds & 24 \\
\hline Stab Wounds & 16 \\
\hline Pedestrians Struck & 3 \\
\hline Motor Vehicle Collisions & 2 \\
\hline \multicolumn{2}{|l|}{$\begin{array}{l}\text { Associated Intraabdominal } \\
\text { Injuries }\end{array}$} \\
\hline Liver & 38 \\
\hline Large Bowel & 18 \\
\hline Kidney & 12 \\
\hline Pancreas & 10 \\
\hline Small Bowel & 8 \\
\hline Stomach & 7 \\
\hline Abdominal Vascular & 5 \\
\hline Extrahepatic Biliary Tree & 3 \\
\hline Spleen & 1 \\
\hline \multicolumn{2}{|l|}{$\begin{array}{l}\text { Associated Non- } \\
\text { Intraabdominal Injuries }\end{array}$} \\
\hline Extremity Non-Vascular & 11 \\
\hline Extremity Vascular & 5 \\
\hline Traumatic Brain Injuries & 4 \\
\hline Pulmonary & 3 \\
\hline Extremity Fractures & 2 \\
\hline Cardiac & 1 \\
\hline
\end{tabular}

vehicle crashes (2). The prevalence of gallbladder injuries remained consistent across the study interval.

Patients with gallbladder injuries were 87\% (39/45) male with a mean age of 27 years (SD: 8.69). The median injury severity score (ISS) was 20 (range: 9-41), with an associated median length of hospital stay of 22 days (range: 0-108). The median length of stay in the ICU was 12 days (range: $1-107)$. Many patients (49\%) presented to the hospital with hemodynamic instability. These patients were transported to the operating room immediately. Gallbladder injuries were diagnosed preoperatively in 7 (16\%) patients (CT imaging), and incidentally during operative exploration in the remaining 38 patients. The Focused Assessment with Sonography for Trauma (FAST) examination was positive in $88 \%$ (7/8) of patients with a preoperative $\mathrm{CT}$ diagnosis of a gallbladder injury. Overall mortality was $24 \%(11 / 45)$. Of the 11 patients who died, causes included exsanguinating hemorrhage secondary to either abdominal vascular (3) or thoracic/ cardiac (3) injuries, delayed complications of multi-organ failure (3), and traumatic brain injuries (2). Associated injuries were present in $44(98 \%)$ patients, including 10 (22\%) pancreatic injuries (Table 1). Of these patients, 5 underwent pancreatic resections and 5 received peripancreatic drainage only. Three different patients (7\%) also had injuries to their extrahepatic biliary ducts (2 common bile ducts and 1 common hepatic duct). The surviving patient underwent a choledocojejunostomy reconstruction. Remaining operative procedures included repair and/or excision of the above mentioned injuries (partial hepatectomy/resectional hepatic debridement (12), colon repair and/or partial colectomy (18), nephrectomy (8), renal repair (3), small bowel repair and/ or excision (8), gastric repair (4), partial gastrectomy (3), abdominal vascular repair (5), and a splenectomy (1)). Nine patients required a repeat laparotomy. Non-abdominal procedures included extremity vascular repair (4), fasciotomy (4), amputation (1), intramedullary nailing (2), thoracotomy with pulmonary resection (2), sternotomy with cardiac repair and pulmonary wedge resection (1), and a craniotomy (1).

Cholecystectomy was performed in 42 (93\%) patients. The remaining 3 underwent local drainage only as part of an initial damage control procedure in patients displaying physiologic exhaustion secondary to concurrent abdominal vascular hemorrhage. Both survivors received a cholecystectomy during the second operative procedure. Outside of the 2 damage control survivors, all cholecystectomies were performed immediately during the first operative procedure ( $<6$ hours after admission). No postoperative complications were directly attributable to the gallbladder injury or subsequent cholecystectomy. Patient complications included bacteremia/sepsis (8), acute lung injury (7), intraabdominal abscess in patients 
with colonic injuries (4), acute kidney injury requiring dialysis (4), wound infection (3), ventilator associated pneumonia (3), deep venous thrombosis (2), abdominal compartment syndrome (1), pulmonary embolus (1), empyema (1), upper gastrointestinal bleeding (1), cerebrovascular accident (1), dehiscence (1), and a pneumothorax related to central line placement (1).

\section{Discussion}

Although the frequency of extrahepatic bile duct injuries in patients with abdominal trauma is moderate ( $2 \%$ to $5 \%)$, gallbladder trauma is quite rare [1,2]. Despite seeing well over 40,000 injured patients during the study period at our urban level 1 center, only 45 gallbladder injuries were noted. As observed in other series, the vast majority were caused by a penetrating mechanism [1].

Operative cholecystectomy following injury was initially described in 1887 [6]. Unfortunately it wasn't until 11 years later that the first report of a survivor receiving cholecystectomy after injury was published [6]. By 1905 however, trauma related cholecystectomies were viewed as "brilliant" in both technique and outcome [7]. Despite these successes, the subsequent 60 years witnessed the propagation of suture repair for tears in the gallbladder to ensure organ preservation [8]. Fortunately, this viewpoint has passed with more modern views stating that cholecystectomy again remains the treatment of choice [9]. This remains true regardless of whether injuries are classified as contusions, avulsions, or lacerations. More specifically, theoretical options such as expectant observation, drainage, and cholecystorrhaphy are employed only in the rarest of circumstances $[1,2]$.

The results of our study, the largest series of gallbladder injuries in the literature, supports cholecystectomy as the primary treatment option. Nearly all patients (93\%) underwent immediate cholecystectomy. The 3 remaining patients were treated with initial drainage in a rapid fashion prior to application of a temporary abdominal closure technique because the patients displayed physiologic exhaustion secondary to massive hemorrhage from intraabdominal vascular injuries. Both initial survivors underwent rapid cholecystectomy on their first return to the operating room (24 and 36 hours after presentation respectively). Furthermore, no patients in the series displayed any morbidity or mortality directly associated with the removal of their gallbladder.

As expected, the outcome of patients with gallbladder injuries is synonymous with the mortality induced from their associated injuries [1,2,10-12]. The 6 patients in our series who died within 24 hours were a result of unresuscitatible cardiac, thoracic or intra-abdominal vascular hemorrhage. The remaining 5 delayed patient deaths were caused by multi-organ failure and/or traumatic brain injuries. This pattern is echoed in other series
$[1,2,13]$. Not surprisingly, patients with injuries to the gallbladder present in accordance with the severity of their concurrent trauma. The patients in our series were critically ill with a mean Injury Severity Score of 20 and mortality rate of $24 \%$. Nearly half of our patients also arrived with hemodynamic instability. Each patient in the series displayed an acute abdomen, and therefore an absolute indication for operative exploration. This concept is also supported elsewhere [1,2].

In addition to the observation that all 3 patients with extrahepatic bile duct trauma also possessed injuries to their gallbladder, 10 patients displayed significant trauma to their pancreas. Among this cohort, half underwent simple drainage (grades I and II) [14], while the remainder required a pancreatic resection (4 distal pancreatectomies and 1 delayed pancreatoduodenectomy).

The limitations of this study are multiple. First, it is retrospective and therefore the possibility of bias cannot be eliminated. Second, we were unable to grade gallbladder injuries with the AAST grading system [15] because of poor documentation. Third, we could not evaluate the potential impact of theoretical risk factors for gallbladder injury (thin walled organ [2], high degree of filling $[2,6,9,16]$, and alcohol ingestion [17]), as this information was not captured in patient charts. Finally, although the series is the largest in the literature $[1,2,18,19]$, it is based on a limited number of patients.

\section{Conclusion}

In summary, the safe and rapid treatment for gallbladder trauma is immediate cholecystectomy. The exception to this remains simple drainage in a patient displaying physiologic exhaustion who also receives a temporary abdominal closure and planned operative re-exploration. Injuries are most often caused by penetrating mechanisms, and clinical presentation, as well as patient outcome is a direct result of the severity of their associated injuries.

\section{Competing interests \\ The authors declare that they have no competing interests.}

\section{Authors' contributions}

CGB, ED and DVF conceived the study, conducted the primary analysis, and drafted the article. AWK, FRS and KBL contributed to the study design and interpretation of all data. All authors contributed to critical revision and approval of the final manuscript.

\section{Acknowledgements}

This manuscript was presented at the Canadian Association of General Surgeons Conference on September 11, 2009 in Victoria, British Columbia, Canada.

\section{Author Details}

1Department of Surgery, University of Calgary, Calgary, Alberta, Canada,

2Department of Critical Care Medicine, University of Calgary, Calgary, Alberta, Canada and ${ }^{3}$ Department of Surgery, Emory University, Atlanta, Georgia, USA

Received: 21 September 2009 Accepted: 15 April 2010

Published: 15 April 2010 


\section{References}

1. Zellweger R, Navsaria PH, Hess F, Omoshoro-Jones J, Kahn D, Nicol AJ: Gallbladder injuries as part of the spectrum of civilian abdominal trauma in South Africa. ANZ J Surg 2005, 75:559-61.

2. Soderstrom CA, Maekawa K, DuPriest RW, Cowley RA: Gallbladder injuries resulting from blunt abdominal trauma. Ann Surg 1981, 193:60-6.

3. Ong ES, Espat NJ: Bile secretion. In Surgery of the liver, biliary tract, and pancreas 4th edition. Edited by: Blumgart LH. Philadelphia: Saunders Elsevier; 2007:72-8.

4. Strasberg SM, Hertl M, Soper NJ: An analysis of the problem of biliary injury during laparoscopic cholecystectomy. J Am Coll Surg 1995, 180:101-25.

5. Beckingham IJ, Nunes QM, Rowlands BJ: Postcholecystectomy problems. In Surgery of the liver, biliary tract, and pancreas 4th edition. Edited by: Blumgart LH. Philadelphia: Saunders Elsevier; 2007:573-85.

6. Norgore M: Traumatic rupture of the gallbladder, case reports and notes on choleperitoneum. Ann Surg 1946, 123:127-34.

7. Ricketts BM: Rupture of the gallbladder (spontaneous and traumatic, with and without operation) an historical review of 273 cases. St Louis Med Rev 1905, 51:108-121.

8. Smith SW, Hastings TN: Traumatic rupture of the gallbladder. Ann Surg 1954, 139:517-20.

9. Knepper PA, Riddell RV, McDaniel JR: Traumatic rupture of the gallbladder without a penetrating wound of the abdominal wall. Arch Surg 1956, 73:371-2

10. McNabney WK, Rudek R, Pemberton LB: The significance of gallbladder trauma. J Emerg Med 1990, 8:277.

11. Penn I: Injuries to the gallbladder. Br J Surg 1962, 49:636-41.

12. Fabian TC, Bee TK: Liver and biliary tract. In Trauma 6th edition. Edited by: Feliciano DV, Mattox KL, Moore EE. New York: McGraw-Hill Medical; 2008:637-60.

13. Bade PG, Thompson SR, Hirschberg A, Robbs JV: Surgical options in traumatic injury to the extrahepatic biliary tract. Br J Surg 1989, 76:256-8.

14. Moore EE, Cogbill TH, Malangoni MA, Jurkovich GJ, Champion HR, Gennarelli TA, McAninch JW, Pachter HL, Shackford SR, Trafton PG: Organ injury scaling II: Pancreas, duodenum, small bowel, colon and rectum. J Trauma 1990, 30:1427-9.

15. Moore EE, Cogbill TH, Jurkovich GJ: Organ injury scaling VI: Extrahepatic biliary, esophagus, stomach, vulva, vagina, uterus (nonpregnant), uterus (pregnant), fallopian tube, and ovary. J Trauma 1995, 39:1069-70.

16. Schechter DC: Solitary wounding of the gallbladder from blunt abdominal trauma. NY State J Med 1969, 69:2895-911.

17. Pirola RC, Davis AE: Effects of ethyl alcohol on sphincteric resistance at the choledocho-duodenal junction in man. Gut 1968, 9:557-60.

18. Bade PG, Thompson SR, Hirshberg A, Robbs JV: Surgical options in traumatic injury to the extrahepatic biliary tract. Br J Surg 1989, 76:256-8

19. Nikhinson RA, Chikhachev AM, Maslov SG, Aliev AD: Blunt and penetrating injuries of gallbladder extrahepatic bile ducts. Klin Khir 1993, 3:21-3.

doi: $10.1186 / 1752-2897-4-3$

Cite this article as: Ball et al., A decade of experience with injuries to the gallbladder Journal of Trauma Management \& Outcomes 2010, 4:3

\section{Submit your next manuscript to BioMed Central} and take full advantage of:

- Convenient online submission

- Thorough peer review

- No space constraints or color figure charges

- Immediate publication on acceptance

- Inclusion in PubMed, CAS, Scopus and Google Scholar

- Research which is freely available for redistribution

Submit your manuscript at www.biomedcentral.com/submit
C Biomed Central 